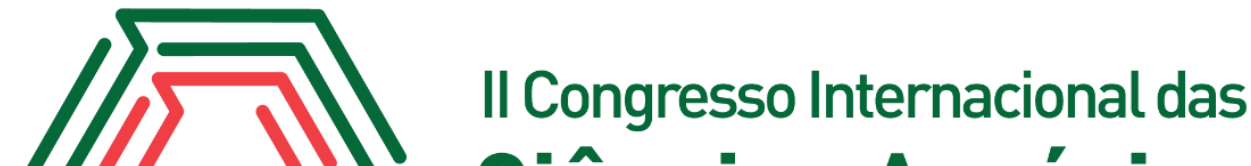 Ciências Agrárias COINTER - PDVAgro 2017
}

\section{ACÚMULO DE FITOMASSA DE CAPIM-CORRENTE EM FUNÇÃO DA ADUBAÇÃO FOSFATADA E NITROGENADA}

Geovane Alves de Moura'; Guilherme Augusto dos Santos Sá2 ${ }^{2}$ Edvaldo Alves de Moura ${ }^{3}$; Fábio Junno Simões de Morais Bezerra ${ }^{4}$; Maurício Luiz de Mello Vieira Leite ${ }^{5}$

\section{Introdução}

O capim-corrente (Urochloa mosambicensis (Hanck.) Dandy) é uma das plantas forrageiras indicadas para o Semiárido do Brasil, devido a alta tolerância ao déficit hídrico e à temperaturas do ar elevadas, além de produzir elevada fitomassa, que pode ser consumida via pastejo ou estocada como feno ou silagem, para uso na alimentação de bovinos, caprinos, ovinos e outros (LEITE et al., 2017). Segundo OLIVEIRA (1999), o capim-corrente requer para o seu pleno desenvolvimento, uma precipitação pluvial anual entre 500 e $1000 \mathrm{~mm}$, sendo uma gramínea muito apreciada pelos animais, capaz de suportar pastejo próximo ao nível do solo e que aos poucos, vem ganhando espaço no Semiárido do Brasil.

É uma planta que possui variações no crescimento dependendo do tipo de solo, e clima na qual se encontra. Para SILVA et al. (1995), a fertilidade do solo intervém na quantidade de forragem produzida e na qualidade.

Esses aspectos reforçam a necessidade do conhecimento das características agronômicas do capim-corrente, pois são escassas as informações disponíveis na literatura sobre as características de crescimento dessa planta forrageira, principalmente nas condições do Semiárido brasileiro. Desse modo, objetivou-se avaliar a produção de fitomassa do capimcorrente, em função da adubação fosfatada e nitrogenada no Semiárido de Pernambuco.

\footnotetext{
${ }^{1}$ Bacharelado em Agronomia, UFRPE-UAST. geovane-am@ hotmail.com

${ }^{2}$ Bacharelado em Agronomia, UFRPE-UAST. gyllerme@ hotmail.com

${ }^{3}$ Bacharelado em Agronomia, UFRPE-UAST. edvaldo10am@ hotmail.com

${ }^{4}$ Bacharelado em Zootecnia, UFRPE-UAST. fabio2014junno@ hotmail.com

${ }^{5}$ Professor Dr. Departamento de Agronomia, UFRPE-UAST. nopalea21@ yahoo.com.br
} 


\section{Fundamentação Teórica}

Dentre as estratégias de manejo que podem alavancar a produtividade de forragem e contribuir para a manutenção de elevados índices de produção animal, a aplicação de fertilizantes se destaca. $\mathrm{O}$ suprimento de nutrientes constitui-se importante fator na nutrição da planta forrageira, tendo em vista que a disponibilidade de nutrientes exerce grande influência na nutrição da planta, que reflete no desenvolvimento vegetal e na recuperação do capim (BONFIM-SILVA \& MONTEIRO, 2010). Dentre os nutrientes considerados essenciais ao desenvolvimento das plantas, o nitrogênio é necessário, sobretudo, para a síntese de ácidos nucleicos, proteínas, hormônios, clorofila e vários outros compostos essenciais ao desenvolvimento das plantas, além de promover aumentos da produção de forragem (SILVEIRA \& MONTEIRO, 2007).

PATÊS et al. (2008) verificaram que houve efeito da interação das doses de nitrogênio e de fósforo sobre a produção de matéria seca (MS) da parte aérea do capim-Tanzânia. LOPES et al. (2011) observaram que a aplicação de doses crescentes de fósforo proporcionou aumento da taxa de acúmulo de MS do capim-xaraés durante o primeiro período seco pós estabelecimento da pastagem.

\section{Metodologia}

A pesquisa foi conduzida de 14 de outubro de 2014 a 08 de janeiro de 2015, em condições de campo, na Universidade Federal Rural de Pernambuco (UFRPE), Unidade Acadêmica de Serra Talhada (UAST), localizada sob as coordenadas geográficas $07^{\circ} 57^{\prime} 01^{\prime \prime}$, S e $38^{\circ} 17^{\prime}$ 53' ' O, altitude de 523 m, situada no município de Serra Talhada, Microrregião do Sertão do Pajeú, Mesorregião do Sertão Pernambucano, região de clima quente e seco.

A análise química do solo, coletado na UAST na profundidade de 0 a $20 \mathrm{~cm}$, foi realizada no Laboratório de Fertilidade do Solo da Empresa Pernambucana de Pesquisa Agropecuária (IPA) e revelou os seguintes teores de nutrientes: $\mathrm{pH}$ (água) $=6,80$; $\mathrm{P}$ (extrator Mehlich I) $=40,0 \mathrm{mg} \mathrm{dm}{ }^{-3} ; \mathrm{K}^{+}=0,45 \mathrm{cmol}_{\mathrm{c}} \mathrm{dm}^{-3} ; \mathrm{Ca}^{2+}=5,50 \mathrm{cmol}_{\mathrm{c}} \mathrm{dm}^{-3} ; \mathrm{Mg}^{2+}=1,6 \mathrm{cmol}_{\mathrm{c}}$ $\mathrm{dm}^{-3} ; \mathrm{Al}=0,0 \mathrm{cmol}_{\mathrm{c}} \mathrm{dm}^{-3}$. O solo, classificado como Luvissolo Crômico (EMBRAPA, 2013), utilizado no experimento, foi destorroado, submetido ao revolvimento para secagem ao ar, homogeneizado e acondicionado em vasos plásticos. Em cada vaso, com capacidade de 9,95 $\mathrm{dm}^{3}$ (22 cm de altura e $24 \mathrm{~cm}$ de diâmetro), disposto aleatoriamente sobre tijolos, colocou-se 
7,2 kg de solo seco ao ar. Duas mudas de capim-corrente, obtidas na UAST, foram plantadas em cada vaso, em 14 de outubro de 2014. Para evitar condição de estresse hídrico, nos primeiros 10 dias, após implantação do experimento, todas as plantas foram mantidas em solo sob condições de capacidade de campo. Após 30 dias do plantio, todas as plantas foram submetidas ao corte de uniformização, a $10 \mathrm{~cm}$ do solo. $\mathrm{O}$ acúmulo de fitomassa do capimcorrente foi avaliado obedecendo ao delineamento experimental inteiramente casualizado, no esquema fatorial $2 \times 2$ (presença e ausência de nitrogênio x presença e ausência de fósforo), com quatro repetições. As fontes de nitrogênio e fósforo utilizadas foram o sulfato de amônio com $20 \%$ de $\mathrm{N}$ e o superfosfato simples com $18 \%$ de $\mathrm{P}_{2} \mathrm{O}_{5}$ solúvel em água, respectivamente. Utilizou-se uma dose de nitrogênio equivalente a $100 \mathrm{~kg} \mathrm{ha}^{-1}$ de $\mathrm{N}$ e uma dose de fósforo equivalente a $150 \mathrm{~kg} \mathrm{ha}^{-1}$ de $\mathrm{P}_{2} \mathrm{O}_{5}$. O nitrogênio e o fósforo foram aplicados em cobertura, imediatamente após o corte de uniformização (14/11/2014). Durante todo o período experimental, os vasos foram mantidos livres de plantas invasoras.

As variáveis estudadas foram produção de matéria verde (PMV), e produção de matéria seca (PMS). Para avaliação das características de crescimento e produção do capimcorrente por ocasião da colheita, foi marcado um perfilho em cada uma das parcelas experimentais. O corte das plantas foi efetuado em 13/12/2014, de forma manual a uma altura de, aproximadamente, $10 \mathrm{~cm}$ do solo, com pesagem em campo para determinação da Produção em Matéria Verde (PMV) do vaso, sendo os valores extrapolados para $\mathrm{kg} \mathrm{ha}^{-1}$. Após a pesagem, o material foi colocado para secagem em estufa de circulação forçada a uma temperatura de $65^{\circ} \mathrm{C}$, até atingir peso constante, para determinação do teor de matéria seca (MS). A partir do peso da biomassa colhida em cada vaso, obteve-se a produção de matéria seca (PMS) e depois se extrapolou esse valor para $\mathrm{kg} \mathrm{ha}^{-1}$.

Os dados foram submetidos a análise de variância para verificação da significância dos tratamentos por meio do Teste F, ao nível de $1 \%$ de probabilidade. Sendo F significativo, as médias dos tratamentos foram comparadas pelo teste de Tukey, ao nível de 5\% de probabilidade. Utilizou-se o programa estatístico R-project versão 2.13.1 for windows.

\section{Resultados e Discussão}

Verifica-se na Tabela 1 que houve efeito significativo $(\mathrm{P}<0,01)$ para produção de matéria verde (PMV) e matéria seca (PMS) do capim-corrente, em função da presença ou ausência de nitrogênio $(\mathrm{N})$ e fósforo $\left(\mathrm{P}_{2} \mathrm{O}_{5}\right)$. 
Tabela 1. Médias de Produção de Matéria Verde (PMV) e Matéria Seca (PMS) do capimcorrente, em função da presença ou ausência de nitrogênio e fósforo. Fonte: Própria

\begin{tabular}{|c|c|c|c|}
\hline $\begin{array}{c}\mathrm{N} \\
\left(\mathrm{kg} \mathrm{ha}^{-1}\right)\end{array}$ & $\begin{array}{c}\mathrm{P}_{2} \mathrm{O}_{5} \\
\left(\mathrm{~kg} \mathrm{ha}^{-1}\right)\end{array}$ & $\begin{array}{c}\text { PMV } \\
\left(\mathrm{kg} \mathrm{ha}^{-1}\right)\end{array}$ & $\begin{array}{c}\text { PMS } \\
\left(\mathrm{kg} \mathrm{ha}^{-1}\right)\end{array}$ \\
\hline 0 & 0 & $5.557,14 \mathrm{bc}$ & $1.444,86 \mathrm{bc}$ \\
\hline 0 & 150 & $2.848,57 \mathrm{c}$ & $712,14 \mathrm{c}$ \\
\hline 100 & 0 & $23.934,29 \mathrm{a}$ & $5.504,89 \mathrm{a}$ \\
\hline 100 & 150 & $22.762,86 \mathrm{a}$ & $5.007,83 \mathrm{a}$ \\
\hline \multicolumn{2}{|c|}{ Média } & $13.775,71$ & $3.167,43$ \\
\hline \multicolumn{2}{|c|}{$\mathrm{CV}(\%)$} & 61,82 & 58,93 \\
\hline
\end{tabular}

Médias seguidas das mesmas letras, nas colunas, não diferem entre si pelo teste Tukey (P > 0,05). $\mathrm{N}=$ nitrogênio; $\mathrm{P}_{2} \mathrm{O}_{5}=$ fósforo. $\mathrm{CV}=$ coeficiente de variação.

A PMV média sem $\mathrm{N}$ foi 4.202, $86 \mathrm{~kg} \mathrm{ha}^{-1}$, inferior a PMV com o uso de $\mathrm{N}$, que foi de $23.348,58 \mathrm{~kg} \mathrm{ha}^{-1}$ (Tabela 1). A adubação nitrogenada promoveu um incremento de $455 \%$ na PMV do capim-corrente. Resultado similar foi observado para PMS, com maior acúmulo de fitomassa do capim-corrente adubado com nitrogênio, independente da adubação fosfatada.

De acordo com SARMENTO et al. (2008), o nitrogênio, entre os nutrientes, é o principal responsável pelo aumento da produção de material seca, indicando, entretanto, que o suprimento de nitrogênio do solo normalmente não atende à demanda das gramíneas, razão que torna a adubação nitrogenada essencial para obtenção de elevados rendimentos forrageiros.

\section{Conclusão}

A adubação nitrogenada, independente do fósforo, proporciona uma maior produção de fitomassa do capim-corrente.

\section{Referências}

BONFIM-SILVA \& MONTEIRO, 2010. Nitrogênio e enxofre na adubação e em folhas diagnósticas e raízes do capim braquiária em degradação. Revista Brasileira de Zootecnia, v.39, n.8, p.1641-1649, 2010. 
EMBRAPA - Empresa Brasileira de Pesquisa Agropecuária - Centro Nacional de Pesquisa de Solos. Sistema Brasileiro de Classificação de Solos. 3. ed. Brasília: Embrapa Solos, 2013. $353 \mathrm{p}$.

LEITE, M. L. M. V.; LUCENA, L. R. R.; SÁ JUNIOR, E. H.; CRUZ, M. G. Estimativa da área foliar em Urochloa mosambicensis por dimensões lineares. Revista Agropecuária Técnica, v. 38, n. 1, p. 9-16, 2017.

LOPES, J.; EVANGELISTA, A. R.; PINTO, J. C.; QUEIROZ, D. S.; MUNIZ, J. A. Doses de fósforo no estabelecimento de capim-xaraés e estilosantes Mineirão em consórcio. Revista Brasileira de Zootecnia, v.40, n.12, p.2658-2665, 2011.

OLIVEIRA, M. C. de. Capim Urochloa: produção e manejo no semi-árido do Nordeste do Brasil. Petrolina, PE: (EMBRAPA-CPATSA. Circular Técnica, 43), 1999. 20 p.

PATÊS, N. M. S.; PIRES, A. J. V.; CARVALHO, G. G. P.; OLIVEIRA, A. C.; FONCÊCA, M. P.; VELOSO, C. M. Produção e valor nutritivo do capim - tanzânia fertilizado com nitrogênio e fósforo. Revista Brasileira de Zootecnia, v.37, n.11, p.1934-1939, 2008.

SARMENTO, P.; RODRIGUES, L. R. A.; LUGÃO, S. M. B.; CRUZ, M. C. P.; CAMPOS, F. P.; FERREIRA, M. E.; OLIVEIRA, R. F. Sistema radicular do Panicum maximum Jacq. cv. IPR-86 Milênio adubado com nitrogênio e submetido à lotação rotacionada. Revista Brasileira de Zootecnia, v. 37, n. 1, p. 27-34, 2008.

SILVA, C. M. M. S.; FARIA, C. M. B. Variação estacional de nutrientes e valor nutritivo em plantas forrageiras tropicais. Pesquisa Agropecuária Brasileira, Brasília, v.30, n.3, p. 413420, mar. 1995.

SILVEIRA, C. P.; MONTEIRO, F. A. Morfogênese e produção de biomassa do capim tanzânia adubado com nitrogênio e cálcio. Revista Brasileira de Zootecnia, v.36, n.2, p.335$342,2007$. 